Etnográfica

Revista do Centro em Rede de Investigação em

Antropologia

vol. $22(2) \mid 2018$

Vol. 22 (2)

\title{
Etnografias urbanas: explorando as cidades contemporâneas - introdução
}

Urban ethnography: exploring contemporary cities - introduction

\section{Lígia Ferro e Renata de Sá Gonçalves}

\section{(2) OpenEdition}

Journals

Edição electrónica

URL: https://journals.openedition.org/etnografica/5360

DOI: 10.4000/etnografica.5360

ISSN: 2182-2891

\section{Editora}

Centro em Rede de Investigação em Antropologia

\section{Edição impressa}

Data de publição: 1 junho 2018

Paginação: 305-310

ISSN: 0873-6561

\section{Refêrencia eletrónica}

Lígia Ferro e Renata de Sá Gonçalves, «Etnografias urbanas: explorando as cidades contemporâneas

- introdução», Etnográfica [Online], vol. 22 (2) | 2018, posto online no dia 07 julho 2018, consultado o

20 janeiro 2022. URL: http://journals.openedition.org/etnografica/5360 ; DOI: https://doi.org/10.4000/ etnografica.5360

Etnográfica is licensed under a Creative Commons Attribution-NonCommercial 4.0 International License. 


\section{Etnografias urbanas: explorando as cidades contemporâneas - introdução}

\section{Ligia Ferro e Renata de Sá Gonçalves}

O texto apresenta o dossiê "Etnografias urbanas: explorando as cidades contemporâneas", focalizando em particular as potencialidades e constrangimentos do fazer etnográfico em contextos urbanos diferentes - Porto (Portugal), Barcelona (Espanha) e Yachay (Equador) -, operacionalizado a partir de formações disciplinares diversas (antropologia, sociologia, psicologia e ciência política). Os trabalhos aqui apresentados resultam de pesquisas atravessadas por eixos analíticos comuns e pelo debate sobre os horizontes da etnografia na cidade, incluindo relevantes questionamentos metodológicos, técnicos e sociopolíticos. Os trabalhos editados oferecem bons exemplos dos principais desafios da investigação atual no âmbito da etnografia urbana.

PALAVRAS-CHAVE: etnografia urbana, cidades, interdisciplinaridade, metodologia, técnicas.

Urban ethnography: exploring contemporary cities - introduction - The dossier "Urban ethnography: exploring contemporary cities" focuses particularly on the potential and constraints of ethnographic practice carried out in different urban contexts - Oporto (Portugal), Barcelona (Spain) and Yachay (Ecuador) - and working from diverse disciplinary backgrounds (anthropology, sociology, psychology and political science). The papers share common analytical axes and are all crossed by the discussion about the possibilities of producing ethnography in the city, including relevant questioning of its sociopolitical, technical and methodological dimensions. Researches included in the dossier offer fine examples of the main challenges faced by current work in urban ethnography.

KEYWORDS: urban ethnography, cities, interdisciplinarity, methodology, methods.

FERRO, Lígia (lferro@letras.up.pt) - IS-UP, Universidade do Porto; CIES-IUL, Instituto Universitário de Lisboa, Portugal.

GONÇALVES, Renata de Sá (renatagoncalves@id.uff.br) - Universidade Federal Fluminense, Brasil. 
O DOSSIÊ QUE AQUI SE APRESENTA SURGE A PARTIR DO PAINEL intitulado "Etnografia(s) urbana(s): explorando as cidades contemporâneas" que organizámos no congresso da Associação Portuguesa de Antropologia (APA), o qual teve lugar na cidade de Coimbra, em Portugal, entre 2 e 4 de junho de 2016. A iniciativa desta organização vem no seguimento do projeto "Cidades em Mudança: Processos Participativos em Portugal e no Brasil”, coordenado por Graça Índias Cordeiro (ISCTE-IUL, Portugal) e Renata de Sá Gonçalves (UFF, Brasil) e financiado ao abrigo de um acordo de cooperação entre a Fundação para a Ciência e a Tecnologia (FCT) do Ministério da Ciência, Tecnologia e Ensino Superior português, e a Coordenação de Aperfeiçoamento de Pessoal de Nível Superior (Capes), do Ministério de Educação brasileiro.

No âmbito deste grupo de discussão, 15 investigadores brasileiros e portugueses apresentaram dez comunicações. Falamos de pesquisadores provenientes das mais variadas áreas das ciências sociais, como a antropologia, a sociologia, a psicologia e a geografia. A discussão e o trabalho conjunto centraram-se nas questões metodológicas que se colocam quando estudamos a vida urbana contemporânea. É de salientar a ativa participação no debate por parte de um público heterogéneo (considerando variáveis como o género, a idade, a formação disciplinar e a fase da trajetória académica), intensamente implicado na investigação etnográfica.

Este dossiê, que temos o prazer de publicar na revista Etnográfica, justifica-se pela relevância e centralidade das abordagens acerca dos modos de fazer, das possibilidades estratégicas e dos métodos de investigação em contextos urbanos. Nele se somam importantes reflexões sobre o que significa fazer etnografia nas cidades contemporâneas, colocando em destaque alguns desafios destas práticas autorreflexivas no presente e para o futuro. Julgamos que a sua leitura será do interesse da comunidade académica constituída por antropólogos, sociólogos e outros cientistas sociais, assim como por todos os que usam a etnografia como principal abordagem metodológica no âmbito do seu trabalho de investigação.

Os estudos urbanos têm-se vindo a construir com recurso a uma variedade de metodologias e técnicas de pesquisa, vivendo da investigação de temas e objetos partilhados por diversas áreas do conhecimento, tais como a sociologia, a antropologia, a história, a geografia, a arquitetura, o urbanismo, a psicologia, entre outras. Deste modo, a etnografia, fazendo indiscutivelmente parte do património disciplinar da "antropologia moderna", tornou-se uma ferramenta de trabalho para profissionais de uma diversidade de disciplinas das ciências sociais e humanas (estando inclusivamente na base da criação da rede internacional de investigadores ETNO.URB - ver < https://etnourb.hypotheses.org >). Foi com este pano de fundo que lançámos um conjunto de desafios aos colegas que trabalham preferencialmente com esta metodologia na cidade. $\mathrm{Na}$ linha da reflexão de Velho (1987), sabemos como "observar o familiar" nas cidades 
contemporâneas nos coloca um conjunto de desafios específicos que importa delinear e discutir.

Os textos aqui reunidos apresentam as suas propostas sobre como operacionalizar a investigação em territórios urbanos, incluindo a tarefa, por vezes árdua, de delimitação dos recortes empíricos da pesquisa. Como se define e redefine o conhecimento no quadro das relações e interações que se estabelecem no terreno? Quais as potencialidades e desafios da etnografia contemporânea como instrumento de trabalho e forma de conhecimento da complexidade urbana? Em que sentidos se colocam questões epistemológicas e éticas neste domínio? Como lidar com a partilha e armazenamento dos dados etnográficos? Quais os modos de fazer possíveis quando fazemos etnografia partilhada na cidade? Qual o papel das novas tecnologias no trabalho etnográfico? As respostas a problemas colocados por situações concretas de investigação oferecem propostas para repensar a etnografia a partir das condições em que é praticada na contemporaneidade. O debate a partir destes desafios no domínio do congresso da APA teve como finalidade munirmo-nos de ferramentas teórico-metodológicas que permitam enfrentar o nosso quotidiano como etnógrafos, descobrindo novas pistas de trabalho para o futuro.

Os três textos aqui apresentados condensam, de certo modo, o trabalho que foi levado a cabo no referido painel temático. A partir de etnografias recentes realizadas nas cidades do Porto (Portugal), Barcelona (Catalunha, Espanha) e Yachay (Equador), os autores debatem usos e estratégias no âmbito do trabalho etnográfico em contextos urbanos, os seus instrumentos de trabalho, bem como as suas potencialidades e desafios teórico-metodológicos, epistemológicos, éticos e sociopolíticos no conhecimento da complexidade urbana. Em particular, todos nos falam sobre como construir recortes empíricos concretos e sobre as inúmeras possibilidades e impossibilidades de operacionalização da etnografia.

Dotadas de grande diversidade e complexidade sociocultural, as cidades apresentam-se nos textos do dossiê não apenas, no sentido estrito, como cenários das práticas, representações e dinâmicas sociais que aí têm lugar, mas como contextos relevantes em si mesmos para a configuração e desenvolvimento dessas realidades, no seguimento de trabalhos prévios nesta área (Cordeiro, Baptista e Costa 2003) e do que tem vindo a suceder em publicações anteriores editadas pelas organizadoras deste dossiê (Ferro, Gonçalves e Raposo 2015; Gonçalves e Ferro no prelo; Ferro et al. 2018). Os processos e reconfigurações dos contextos e dinâmicas urbanas põem em xeque, inclusive, as nossas categorias analíticas e conceitos e é nesse sentido que as explorações que integram este dossiê dão um importante contributo para o debate.

Joan Josep Pujadas apresenta-nos uma reflexão sobre a mobilidade na área metropolitana de Barcelona e as potencialidades da etnografia em articulação com a técnica do shadowing (Wolcott 1973; Czarniawska 2007, 2014; Gaggiotti 2010, 2011; Jirón 2007, 2008, 2011) como forma de a abordar, com o seu 
texto intitulado "Etnografía móvil, entre el sombreado y el acompañamiento: notas a partir del estudio de la movilidad cotidiana en la Región Metropolitana de Barcelona (RMB)". O texto, escrito a partir da experiência antropológica sólida do seu autor, convida-nos a pensar no modo como a etnografia, estratégia metodológica holística, orienta a aplicação de técnicas de pesquisa como a observação e o shadowing, permitindo estudar de modo aprofundado os fenómenos que pautam a vida na metrópole: a mobilidade, a simultaneidade, a fragilidade e a multiterritorialidade. Trata-se de uma pesquisa colaborativa, em que os seus protagonistas apresentaram graus diferentes de envolvimento e participação, a qual permitiu refletir também sobre alguns limites éticos que a técnica mencionada levanta, quando aplicada no quadro abrangente de uma etnografia de relevante fôlego.

Os psicólogos Simão Mata e Luís Fernandes focalizam a revisitação etnográfica e a técnica do go-along (Kusenbach 2003) no texto "Questões metodológicas de uma revisitação etnográfica a territórios psicotrópicos do Porto”. Partindo da longa experiência etnográfica acumulada por Luís Fernandes nos bairros portuenses do Aleixo, Pinheiro Torres e Pasteleira, os autores encetam um processo de revisitação etnográfica partilhada destes territórios. Sendo a etnografia uma abordagem que implica longa permanência no terreno para recolha de dados, é com frequência que voltamos aos territórios estudados e é também nesses momentos que somos confrontados com várias questões. Como realizar a leitura dos dados recolhidos no passado e no presente? Qual o peso das mudanças dos contextos urbanos nesse processo interpretativo? Estas são algumas das questões que nos vão inquietando durante os processos de revisitação etnográfica. Os autores partem de reflexões teóricas como a de Burawoy (2003), colocando à discussão as dimensões empíricas de uma revisitação etnográfica nos referidos territórios da cidade do Porto.

A partir de um trabalho interdisciplinar que cruza formações na área da sociologia, da antropologia e da ciência política, Miquel Férnandez González, Maribel Cadenas Álvarez e Thomas Purcell discutem os constrangimentos políticos à realização de etnografia em Yachay, no Equador, no domínio do seu texto "Urbanismo utópico, realidades distópicas: una etnografía (im)posible en Yachay, 'ciudad del conocimiento'". A censura de uma etnografia indesejada é colocada a nu neste artigo conjunto, levando-nos a refletir sobre o cariz incómodo da investigação em ciências sociais no nosso tempo, em particular quando a mesma é dotada de um grau considerável de aprofundamento teórico -empírico, como sucede no âmbito do trabalho etnográfico. Este texto constitui ainda um contributo de relevo para o designado debate sobre as "smart cities" ou "cities from scratch" (Carvalho 2015; Datta 2015; Luque-Ayala e Marvin 2015), mostrando como as "utopias planificadas" vivem do controlo da informação e, por conseguinte, das eventuais investigações independentes e críticas que se possam realizar nesses contextos. 
Assim, os três trabalhos resultam de pesquisas atravessadas por eixos analíticos comuns e pelo debate sobre os horizontes do fazer etnográfico, incluindo os constrangimentos e possibilidades do ponto de vista metodológico, técnico e sociopolítico. $\mathrm{Na}$ nossa perspetiva, estes eixos partilhados caraterizam, de certo modo, a investigação atual no âmbito da etnografia urbana. Destacamos pelo menos dois eixos fundamentais que atravessam os três trabalhos:

- A articulação entre uma abordagem metodológica mais abrangente e holística, como a etnografia, e um conjunto de técnicas inovadoras e pouco exploradas para o estudo da realidade urbana, em particular a técnica do shadowing, usada por Pujadas, e a do go-along, a que recorrem Mata e Fernandes. Partindo de contextos urbanos em permanente mudança, os autores exploram as possibilidades de instrumentos concretos no que diz respeito à recolha de dados etnográficos.

- Os limites éticos e os constrangimentos sociais e políticos que configuram a concretização prática da investigação etnográfica. Pujadas levanta pistas para aplicar a técnica do shadowing, seguindo os movimentos das pessoas na metrópole sem romper com o código ético que rege o trabalho etnográfico. Mata e Fernandes questionam os seus próprios limites enquanto etnógrafos, partindo do esforço de reconhecimento dos limites geográficos e sociais dos territórios da pesquisa. Férnandez, Cadenas e Purcell analisam as implicações para a prática de dinâmicas políticas de censura de uma etnografia indesejada em Yachay.

As potencialidades e limites da etnografia em contextos definidos levam-nos a uma reflexão sobre cidades em mudança e as possibilidades da investigação etnográfica face a essas mudanças. Os três artigos apresentam, de forma criativa, pistas muito relevantes para pensar a abordagem etnográfica à vida urbana, considerando e interpretando a sua grande complexidade. Esperamos que os contributos aqui apresentados possam constituir novos pontos de partida para investigações e reflexões futuras. 


\section{BIBLIOGRAFIA}

BURAWOY, Michael, 2003, "Revisits: an outline of a theory of reflexive ethnography", American Sociological Review, 68 (5): 645-679.

CARVALHO, Luís, 2015, "Smart cities from scratch? A socio-technical perspective", Cambridge Journal of Regions, Economy and Society, 8 (1): 43-60.

CORDEIRO, Graça Índias, Luís Vicente BAPTISTA, e António Firmino da COSTA, 2003, Etnografias Urbanas. Oeiras, Celta Editora.

CZARNIAWSKA, Barbara, 2007, Shadowing and Other Techniques for Doing Fieldwork in Modern Societies. Malmö, Liber.

CZARNIAWSKA, Barbara, 2014, "Observation on the move: shadowing”, em B. Czarniawska, Social Science Research: From Field to Desk. Los Angeles, Sage, 43-56.

DATTA, Ayona, 2015, "New urban utopias of postcolonial India: 'entrepreneurial urbanization' in Dholera smart city, Gujarat”, Dialogues in Human Geography, 5 (1): 3-22, DOI: $10.1177 / 2043820614565748$.

FERRO, Lígia, et al. (orgs.), 2018, Moving Cities: Contested Views on Urban Life. Wiesbaden, Springer.

FERRO, Lígia, Renata GONÇALVES, e Otávio RAPOSO (orgs.), 2015, Expressões Artísticas Urbanas: Etnografia e Criatividade em Espaços Atlânticos. Rio de Janeiro, Editora Mauad/FAPERJ.

GAGGIOTTI, Hugo, 2010, "Official chronicles of corporate globalization and unofficial stories of international mobility: resisting patronage of meanings?", Journal of Organizational Change Management, 23 (2): 157-165.

GAGGIOTTI, Hugo, 2011 , "Narrating expatriation and making sense of the globalization experience", em E. Bonet et al. (orgs.), Rhetoric and Narratives in Management Research. Sant Cugat, ESADE, 293-306.

GONÇALVES, Renata de Sá, e Lígia FERro (orgs.), no prelo, Cidades em Mudança: Processos Participativos em Portugal e no Brasil. Rio de Janeiro, Mauad Editora.

JIRÓN, Paola, 2007, "Unravelling invisible inequalities in the city through urban daily mobility: the case of Santiago de Chile", Swiss Journal of Sociology, 33 (1): 45-68.

JIRÓN, Paola, 2008, Mobility on the Move: Examining Urban Daily Mobility Practices in Santiago de Chile. Londres, London School of Economics and Political Science.

JIRÓN, Paola, 2011 , "On becoming 'la sombre/the shadow', em M. Buscher et al. (orgs.), Mobile Methods. Londres, Routledge, 36-53.

KUSENBACH, Margarethe, 2003, "Street phenomenology: the go-along as ethnographic research tool”, Ethnography, 4 (3): 455-485.

LUQUE-AYALA, Andrés, e Simon MARVIN, 2015, "Developing a critical understanding of smart urbanism?", Urban Studies, 52 (12): 2105-2116, DOI: 10.1177/0042098015577319.

VELHO, Gilberto, 1987, "Observando o familiar", em G. Velho, Individualismo e Cultura: Notas para Uma Antropologia da Sociedade Contemporânea. Rio de Janeiro, Jorge Zahar.

WOLCOTT, Harry, 1973, The Man in the Principal's Office: An Ethnography. Walnut Creek, CA, Altamira Press. 